\title{
The Employer-Employee Relationship as a Building Block for Ethics and Corporate Social Responsibility
}

\author{
Robyn A. Berkley • George Watson
}

Published online: 15 September 2009

(C) Springer Science + Business Media, LLC 2009

One of the great challenges of pursuing the ideals of ethical behavior is discovering how to implement such an ideal at the applied level. As the unremitting stream of bad ethical news flows from the Wall Street Journal and other media outlets testifies, academicians have not performed especially well in applied ethics. In fact, as of this writing, business schools tend to downplay the importance of ethics relative to functionalist skills, or resist the alternative of establishing a course in ethics, let alone, minors or concentrations in the topic. Consequently, we were delighted to be called upon to forge this special issue addressing ways to balance ethics, social responsibility and the rights of employees and employers.

There are numerous complex cases focusing on the practice of human resource management. We anticipate, as international economies continue to integrate, more ethical issues involving workers will emerge. Some of us can, all too clearly, recall the quandary of whether it was better for the injured party that American firms continue to operate in the apartheid regimes of South Africa, or pull out. We face much the same predicament today when we consider the charges of child, or otherwise "exploitive" labor practices, in many developing economic regions. We hope, and believe, that the following papers will provoke ideas about what it means to balance organizational ethical responsibilities.

Ethics and corporate social responsibility (CSR) works at multiple levels in organizations, beginning at the individual level and the accountability of individual employees and managers, to the responsibility of corporations to their employees and the communities at large through CSR. One important theme we wanted to address in this special issue is the importance of considering the employee in an organization's ethical and CSR assessment of stakeholders. While the primary stakeholder, shareholders, tends to get most of the media's and the management team's attention, the employee is one of the most important stakeholders organizations can face. Unfortunately, these individuals tend to get consistently ignored when considering the scope of ethical decisions. The impact of the Enron debacle comes to mind whereby employees lost not only their jobs in the aftermath, but also lost their retirement investments as most organizational incentives came to employees in the form of company stock and stock options. Along with the organization's 
responsibilities to the employees, it is also important to acknowledge that the relationship is reciprocal and employees owe that same consideration to the employer. Our goal was to underscore the importance of developing and nurturing the employer-employee relationship in ways that contributes to the organization's ethical and CSR agenda.

While legislation such as Sarbanes-Oxley (SOX) has addressed the importance of ethics programs and training, as well as fiscal accountability to the shareholders, little has addressed the accountability the organization has to its employees through organizational policies and procedures or legislative safety nets. Consequently, as noted, we have witnessed thousands of employees lose their retirement savings and their livelihoods, while the opportunity costs associated with remaining committed and loyal to their employer has left them powerless to regain their lost wealth. Nord and Riggs Fuller's paper addresses this problem. For some time Nord and Fuller have been advocating a larger, more enlightened model for managing employees. Their contribution to this journal extends their customary eloquence in arguing on behalf of employee involvement. In Increasing Corporate Social Responsibility Through an Employee Centered Approach these scholars argue that corporate social responsibility can be effective using a bottom-up approach. Calling upon the energy, insights and experience of lower tier workers not only increases employee involvement and commitment, but similar to the Nordstrom's experience they cite, enhances effective business practices to all stakeholders. Although higher tier executives can establish an overall, long-term strategy for CSR, the smaller, employee-initiated steps, can achieve the objective of higher levels of organizational involvement in social responsibility as well.

Cortini recognizes that the employee-employer relationship is not a static or monolithic structure but rather a relationship shaped by market trends, environmental conditions and especially emerging technologies. At the unfamiliar edge of these advances many corporate leaders make decisions that are ethically questionable, and as Markel and Barkley point out, new challenges require new solutions. New Horizons in Corporate Social Responsibility and Employee/Employer Relationships: Challenges and Risks of Corporate Weblogs addresses the role of corporate policies on weblogs as both a means to enhance CSR as well as diminish its impact among employees and consumers. Cortini remarks on the importance of blogs for both external and internal stakeholders, but particularly addresses the impact of restrictive policies on internal stakeholders, the employees. Particularly, she makes the case that restrictive corporate policies on weblogs violates employee rights for freedom of speech and freedom of expression, thereby having a negative impact on the ethical and philanthropic sides of CSR. Key stakeholders become restricted in an important form of organizational communication. Additionally, the organization may be perceived negatively by potential employees who seek a company with a more generous perspective on organizational communication technologies, which Cortini cleverly connects with the CSR philosophy of a firm. Cortini concludes her paper making recommendations on how to balance corporate security with generous blogging policies to enable the organization to deal with corporate social responsibilities issues.

Although most of us have come to accept that workplace restrictions in the employeeemployer relationship play a role in corporate profitability and competitiveness, there are workers among us who are disadvantaged by this normative structure through the disabilities they bear. Markel and Barclay's paper focuses on this issue. Despite the passage of legislation (The Americans with Disabilities Act) that addressed physical accommodations for the disabled, underemployment of this group remains a substantial issue. In Addressing the Underemployment of Persons with Disabilities: Recommendations for Expanding Organizational Social Responsibility, they argue that employing Persons 
With Disabilities (PWD) is a social imperative. Beyond the legal obligations an organization has to provide accommodations, Markel and Barclay provide a series of questions for organizations to consider in order to make their organizations MORE accommodating and improve the working conditions of PWD.

As editors concerned about ethics in the workplace we wanted to also emphasize the responsibility of the employee to be honest and forthright with their employer. If the employee-employer relationship is to evolve into one of mutual trust and commitment then each of us are obligated to adhere to ethical standards in our interactions. Kaplan and Fisher look closely at the role of the résumé in establishing important first impressions and expectations. A Rose by Any Other Name: Identity and Impression Management in Résumés focuses on two factors related to impression management in résumés: methods used to control impressions and motivations to control impressions. These authors develop a typology for understanding ethical concerns relative to impression management by job seekers. In this typology Kaplan and Fisher outline the methods of impression management, for example, including or withholding certain demographic information for the purpose of seeking advantages over other applicants. In the editors' view Kaplan and Fisher provide a needed and excellent framework for understanding, identifying and evaluating impression management techniques in résumés.

It has become increasingly apparent that an international perspective in adaptation of ethical standards is becoming central to success outside of the corporation's home country. At times, policies in place (or not in place) in a particular geographic region may profoundly influence perceptions of organizational intent and sensitivity. Laouisset describes such a case from the United Arab Emirates. In Organizational Commitment to Ethics and International Ethical Perspectives: UAE Banks as a Case Study, statistically significant correlations between organizational ethics and objective organizational performance as indicated by productivity, quality, and employee turnover and as well as organizational performance versus the industry as a whole were found. In addition indications of productivity, profitability, quality, and customer retention have been demonstrated by the data. Statistically significant relationships between organizational ethics and objective financial performance as indicated by income relative to total sales have been similarly demonstrated. This study adds to the mounting evidence regarding the important business effects of socially responsible and ethical policies.

It is our hope, in developing this special issue, that we have adequately underscored the importance of the employer-employee relationship as a fundamental building block to an organization's ethics and corporate social responsibility policy. As academics, our responsibility to the field at large as well as to our students in the classroom requires us to continually reinforce the notion that "business ethics" is not an oxymoron, but an important attribute to running a successful and responsible business organization. We are grateful to the Managing Editor of ERRJ, to the authors and to the reviewers for their efforts in making this important special issue possible. We hope that it advances our collective abilities to "do the right thing" in an increasingly complex, diverse and competitive world. 